\title{
Prevention of mood disorder after stroke: a randomised controlled trial of problem solving therapy versus volunteer support
}

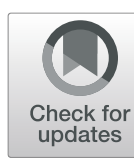

Kate Hill ${ }^{1 *}$ (D, Allan House ${ }^{1}$, Peter Knapp ${ }^{2}$, Carrie Wardhaugh ${ }^{3}$, John Bamford ${ }^{4}$ and Andy Vail ${ }^{5}$

\begin{abstract}
Background: Mood disorder after stroke is common but drug and psychosocial treatments have been assessed with disappointing results. Preventing mood disorder from developing in the first place could be a better approach and might reduce the need for pharmacotherapy in this predominantly older patient group. We used a brief problem-solving therapy and evaluated its effect in reducing mood disorder in the 12 months after stroke.

Methods: A 3-group, parallel, randomised controlled trial. Four hundred fifty patients with stroke were randomised within 1 month of hospital admission to problem-solving therapy from a psychiatric nurse, non-specific support given by volunteers or treatment-as-usual. Follow up took place at 6 and 12 months after stroke. Standardised measures of mood (Present State Examination, GHQ-28), cognitive state (mini-mental state examination) and function (Barthel ADL index, Frenchay Activities Index) were taken at baseline, 6 and 12 months after randomisation. Satisfaction with care was recorded at follow up.

Results: At 6 months, all psychological and activity measures favoured problem-solving therapy. At 12 months, patients in the problem-solving therapy group had significantly lower GHQ-28 scores and lower median Present State Examination symptom scores. There were no statistically significant differences in activity. The problem-solving therapy group were more satisfied with some aspects of care.

Conclusions: The results are encouraging and suggest it is possible to prevent mood disorder in stroke patients using a psychological intervention. The differences between the groups at 12 months may indicate a sustained impact of psychological therapies, by comparison with non-specific support.
\end{abstract}

Trial registration: ISRCTN: ISRCTN33773710 Registered: 23/01/2004 (Retrospectively).

Keywords: Stroke, Cerebrovascular accident, Depression, Mood disorders, Problem solving, Cognitive therapy, Prevention

\section{Background}

Stroke patients are a predominantly older group and around $50 \%$ of acute stroke survivors have residual major physical or cognitive deficits. Given the need for patients to cope with the complex physical and social sequelae of stroke, the demands of recovery and rehabilitation, and the risk of recurrent stroke, it is not surprising that mood disorder, usually manifesting as anxiety or depression after stroke, is common. The consequences of

\footnotetext{
* Correspondence: k.m.hill@leeds.ac.uk

'Leeds Institute of Health Sciences, University of Leeds, Worsley Building (Rm 11.57), Clarendon Way, Leeds LS2 9NL, UK

Full list of author information is available at the end of the article
}

unreconciled emotional distress can be reduced quality of life and impaired progress in physical and social rehabilitation. A number of drug and psychosocial treatments have been assessed in clinical trials but the results have been disappointing. Drug trials have suggested a role for antidepressants in both treatment and prevention, but the trials are generally of poor quality and do not provide sufficient information to judge their true costs and benefits $[1,2]$ Psychosocial interventions have similar methodological problems [3]. The latter are popular with patients but there is conflicting evidence for their effectiveness in either treating or preventing anxiety and depression $[4,5]$. 
Nonetheless, psychosocial interventions may have a role in preventing mood disorder after stroke, as recent reviews have concluded, and there is still a need for more trials in this area [6, 7].

\section{Aims and objectives}

This study aimed to evaluate the effect of a brief psychological treatment: problem-solving therapy for reducing mood disorder in the 12 months after stroke [8]. We used two comparison groups: treatment-as-usual, and an attention control group that received non-specific support given by volunteers. Outcomes were measured quantitatively by a widely-used self-report questionnaire, the 28-item General Health Questionnaire (GHQ-28) [9] and by scores derived from a standardised psychiatric interview the Present State Examination: Short Form (PSE) [10]. Our secondary hypotheses were that patients in the problem-solving therapy group would be less likely to have a diagnosable depressive disorder at follow up, would have better social function and would be more satisfied with their care.

\section{Methods}

Study design and participants

A 3-group, parallel, randomised controlled trial.

\section{Sample}

Patients admitted with first ever or recurrent stroke (diagnosed on clinical history and signs, supplemented by CT brain scan when ordered by clinician) to hospitals in Leeds and Bradford. We were notified of stroke admissions in the two Leeds trusts by the Leeds Stroke Database. In Bradford we contacted admitting wards each week.

\section{Inclusion criteria}

Adults admitted to hospital with first ever or recurrent stroke (other than subarachnoid haemorrhage) within the past month; who were local residents and able to give written consent.

\section{Exclusion criteria}

Patients who were: too ill to interview within 1 month of stroke; unable to participate through impaired speech, cognition or use of English; living in a residential home; had a serious concurrent illness, which was likely to dominate the pattern of care or were participating in another rehabilitation trial.

\section{Randomisation and masking}

The trial had three arms: problem-solving therapy from a psychiatric nurse, non-specific support given by volunteers or treatment-as-usual. We screened all notifications of stroke admissions, and after obtaining verbal consent for the initial assessment we undertook a baseline interview and a Mini-Mental State Examination (MMSE) [11]. Randomisation was third party, after a telephone call from a research interviewer to a remote trials office. Random allocation was generated by computer in the trials office in blocks of 15, stratified by admitting NHS trusts. Eligible patients were then asked to give written consent to the treatment to which they had been randomised, and to be followed up at 6 and 12 months. If the patient refused the intervention we asked them to consent to follow-up. Patients were sent a letter confirming their participation and giving the name of their volunteer or nurse, as appropriate, and the planned follow-up dates. In this way, patients were not aware that their treatment was being randomly allocated, and did not know that other patients were receiving a different treatment. This design, which is a variant of Zelen's procedure [12], was approved by the three local research ethics committees that reviewed the study.

Patients were not masked to their allocation as this is clearly impossible to achieve with this type of intervention. However, as a result of the randomisation procedure patients were unaware of other treatment allocations.

\section{Interventions and comparators Problem-solving therapy}

This short-term therapy was delivered in the patient's home, after discharge, by one of two Community Psychiatric Nurses employed specifically for the study. The aim was to improve the patient's problem solving skills, so that the patient feels he or she is taking control of coping. Improved coping skills should result in reduced psychological distress and rates of depression. The therapist followed a manual in helping the patient to identify and prioritise problems, set goals and identify solutions to the problems, choose and try a plausible solution and then re-assess in the light of the results. The therapy had six sessions: identifying stroke related problems including gaps in knowledge about stroke; identifying nonstroke problems; identifying available external resources; identifying personal coping resources; looking at the problem-solving process, and summarising the process. The therapy has been described in more detail elsewhere [13]. The six sessions were planned to be given in $6 \mathrm{~h}$, about a fortnight apart, with the patient doing 'homework' between each meeting. One benefit of a manualbased therapy is that the therapist can give more or less time to each session by monitoring the patient's progress. The therapy was adaptable to be used with or without a carer present. The therapists received training and regular clinical supervision from a specialist liaison psychiatrist (AH). The therapy was not given if the patient was discharged to residential care or remained in hospital 6 months after stroke. 


\section{Non-specific support}

One of 47 volunteers recruited to the study was assigned to provide talking (non-specific) support. The volunteers attended a training meeting that focussed on the consequences of stroke. More than half the volunteers had personal or family experience of stroke. We asked the volunteer to visit the patient 6-8 times and paid travel expenses. For practical reasons the volunteers began their visits to the patient soon after randomisation, sometimes before the patient was discharged.

\section{Treatment as usual}

No additional effort was made, during the course of the trial, to enhance routine psychiatric care in stroke services. At the time of the trial, no stroke service in Leeds or Bradford had dedicated clinical psychology or psychiatry time available for the treatment of mood disorders associated with stroke, although referral was possible from all services for mental health assessment and treatment of cases identified by stroke staff as requiring specialist care.

\section{Outcome assessment}

A trained interviewer obtained personal and social details, and undertook the following assessments during the initial interview:

The Mini-Mental State Examination (MMSE) [11], a brief screen for cognitive dysfunction. It is scored 0-30 with higher scores indicating better function.

The Barthel index [14], which assesses activities of daily living skills. It is scored $0-20$, with higher scores indicating greater abilities. The patient's self-reported pre-stroke and post-stroke abilities were assessed.

The Frenchay Activities Index [15] is a measure of social function, scored 0-45, with higher scores indicating greater function. It is broader in scope than the Barthel index, including items to assess frequency of shopping, travel, hobbies, etc. The patient's self-reported pre-stroke activities were assessed.

The Present State Examination: short form (PSE) [10] is a semi-structured, standardised psychiatric interview from which is derived an index of definition. The index has a range $1-7$, with a score of $\geq 5$ indicating probable psychiatric disorder; we gave each of these cases a psychiatric diagnosis according to the research criteria of ICD-10.

The General Health Questionnaire (GHQ-28) [9] is a measure of psychological distress scored $0-28$, with higher scores indicating greater distress. Scores on the GHQ can be used to identify probable psychiatric disorder: for neurological in-patients the threshold is $\geq 12$ and among outpatients the threshold is $\geq 9$ and above.
The patients also completed an adapted version of a scale to assess satisfaction with aspects of care given in hospital and after discharge [16].

Follow up assessments took place in the patient's home with an interviewer who was not informed of the treatment allocation of the patient. Patients who received problem-solving were asked by the therapist not to reveal their allocation. To test the extent of unmasking of outcome assessors, we asked the interviewer to guess the allocation of 127 patients seen at 12 months.

Primary assessments were PSE and GHQ-28 at 12 months. Secondary assessments were: the Barthel index, the Frenchay Activities Index, patient satisfaction, medication use, and contacts with health and social services at 12 months, and all the above at 6 months.

\section{Sample size calculation}

The sample size of 450 was calculated to give $80 \%$ power to detect a 2-point difference in GHQ score, including an estimate of $20 \%$ lost to follow-up, through death and refusals, randomly distributed between the groups. We based the sample size calculation for the study on producing a 2-point change because no minimally clinically important difference has been defined for the GHQ since it is designed primarily as a screening tool.

\section{Statistical analysis}

Prior to starting the study we planned to undertake two forms of analysis: in the first (Phase 1) we planned to compare the outcome data for all three groups at $6 \&$ 12 months to test variation between them. In the second (Phase 2) we planned to compare problem-solving therapy with the other 2 groups to test its benefit.

Our methods of analysis included the Kruskal-Wallis (non-parametric) analysis of variance to examine ordinal scales in Phase 1. Other measures were dichotomised and analysed using logistic regression in Phase 2 of our plan. We used therapy as the 'baseline' group, since we planned the trial to compare it with both treatment-asusual and non-specific support, similar to that provided in previous studies [17].

\section{Results}

\section{Recruitment}

We received notification of almost 1900 stroke admissions over 23 months (see Fig. 1), of which 542 $(28.5 \%)$ patients were eligible for inclusion. Of this total $450(83.0 \%)$ patients agreed to the baseline interview and were randomised. Two patients were randomised in error: one who had not suffered a stroke and another who also suffered dementia. These patients were withdrawn. The random allocation resulted in similar numbers and distribution of baseline variables in the three groups (see Table 1). The three 


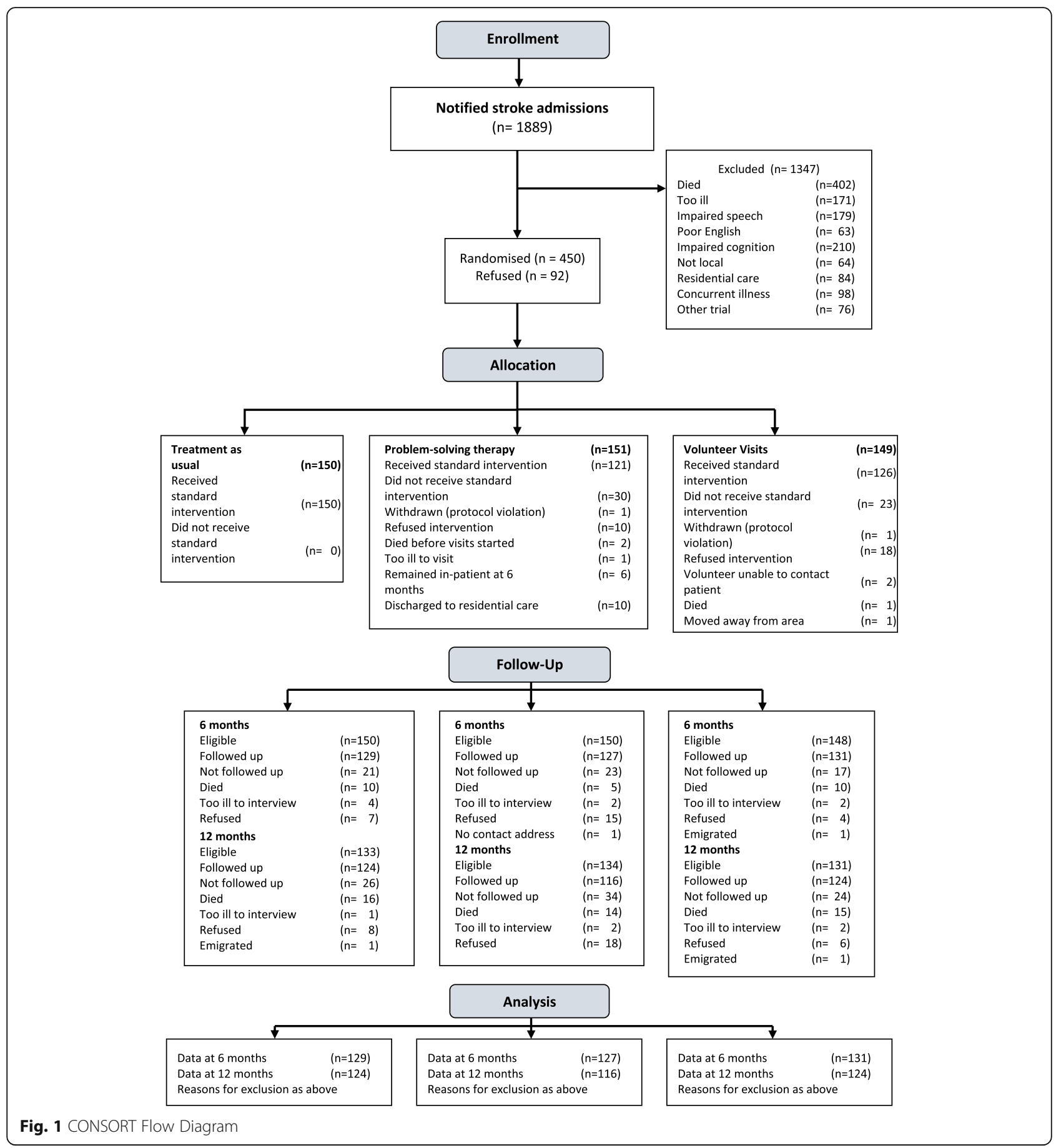

methods of assessing psychiatric disorder produced similar rates: approximately one fifth of patients were identified as having a mood disorder within 1 month of stroke.

At the 12 month interview we were able to interview $124 / 133(93.2 \%)$ eligible patients in treatment as usual, $116 / 134$ (86.6\%) in problem-solving therapy, and 124/ 131 (94.6\%) in volunteer support (see Fig. 1).

\section{Contact with intervention}

Thirty patients randomised to problem-solving therapy (19.9\%) did not receive any therapy intervention. For the majority (19) this was because they were unable to do so (see Fig. 1), but 10 patients refused the intervention either immediately after randomisation or after discharge when the therapist phoned to make the first appointment and one was withdrawn. Remaining patients 
Table 1 Baseline data for all patients and the three randomised groups

\begin{tabular}{lllll}
\hline Baseline variable N (\%) or Median (IQR) & All patients & Problem solving therapy & Volunteer support & Treatment as usual \\
\hline Female & $207(46 \%)$ & $66(44 \%)$ & $76(51 \%)$ & $65(43 \%)$ \\
Age & $72(65-79)$ & $71(65-79)$ & $72(64-78)$ & $74(68-80)$ \\
Previous stroke & $94(21 \%)$ & $36(24 \%)$ & $26(18 \%)$ & $32(21 \%)$ \\
Home owner & $249(56 \%)$ & $78(52 \%)$ & $86(58 \%)$ & $85(57 \%)$ \\
Lived alone pre-stroke & $175(39 \%)$ & $64(43 \%)$ & $52(35 \%)$ & $59(39 \%)$ \\
No named carer & $46(10 \%)$ & $17(11 \%)$ & $14(9 \%)$ & $15(10 \%)$ \\
In any paid work (pre-stroke) & $131(29 \%)$ & $36(24 \%)$ & $45(30 \%)$ & $50(33 \%)$ \\
Initial hospital stay (days) & $27(12-60)$ & $26(13-64)$ & $27(12-71)$ & $26(15-55)$ \\
Pre-stroke Barthel $<20$ & $132(29 \%)$ & $51(34 \%)$ & $43(29 \%)$ & $38(25 \%)$ \\
Pre-stroke Frenchay & $27(21-34)$ & $26(11-33)$ & $14.5(9-19)$ & $29(20-34)$ \\
Post-stroke Barthel & $15(9-18)$ & $14(9-18)$ & $26(23-28)$ & $15(9-18)$ \\
MMSE score & $26(23-28)$ & $26(23-28)$ & $5(2-10)$ & $26(23-27)$ \\
GHQ-28 total score & $5(2-9)$ & $6(2-10)$ & $27(18 \%)$ & $5(2-9)$ \\
GHQ-28 score $\geq 12$ & $85(19 \%)$ & $29(19 \%)$ & $5(2-8)$ & $29(20 \%)$ \\
PSE total symptom score & $5(2-9)$ & $5(3-9)$ & $35(24 \%)$ & $4(2-7)$ \\
PSE Index of definition $\geq 5$ & $102(23 \%)$ & $34(23 \%)$ & $34(23 \%)$ & $33(22 \%)$ \\
Major depressive episode & $100(22 \%)$ & $36(24 \%)$ & $51(34 \%)$ & $30(20 \%)$ \\
Any depressive episode & $145(32 \%)$ & $51(34 \%)$ & $43(29 \%)$ \\
\hline
\end{tabular}

received between 1 and 10 sessions (median 5) during the 4 months after stroke. Twenty-three patients (15.4\%) randomised to support did not receive any volunteer visits. The commonest reason was patient refusal, often immediately after randomisation. Patients received between 1 and 42 volunteer contacts in the first 12 months after stroke (median 6) and many volunteers maintained patient contact beyond 6-8 visits and after we had stopped paying their travel expenses.

\section{Functional and psychological scores at $\mathbf{6}$ and 12 months}

Patients randomised to problem-solving therapy had non-significantly lower Barthel and Frenchay scores compared to the volunteer support and treatment as usual groups at 6 months. At 12 months, patients in the problem-solving group had lower GHQ scores, with a median score 2 points lower than the treatment as usual group and one point lower than the volunteer support group. When GHQ scores were converted into caseness scores this difference was no longer significant. There was also evidence of differences between the three groups in their Barthel or Frenchay scores similar to those observed at 6 months. Patients in the problemsolving group had lower scores but these differences were non-significant. See Table 2.

\section{Outcomes}

The psychological scores were converted to caseness (a PSE index of definition $\geq 5$; a GHQ score $\geq 9$ or a major depression diagnosis) we found that the problem-solving therapy group had lower levels of major depression and fewer patients had an index of definition of 5 or above

Table 2 Functional and psychological scores at 6 and 12 months

\begin{tabular}{|c|c|c|c|}
\hline Variable Scores at 6 months median (IQR) & Problem solving therapy & Volunteer support & Treatment as usual \\
\hline Barthel Index & $17(12-20)$ & $18(13-20)$ & $18(15-20)$ \\
\hline Frenchay Activities Index & $10(3-20)$ & $12(3-23)$ & $12(5-23)$ \\
\hline GHQ-28 score & $4(2-8)$ & $4(2-9)$ & $5(2-9)$ \\
\hline PSE total symptom score & $4(2-8)$ & $6(2-9)$ & $5.5(2-10)$ \\
\hline Variable Scores at 12 months median (IQR) & Problem solving therapy & Volunteer support & Treatment as usual \\
\hline Barthel Index & $17(12-20)$ & $18(13.5-20)$ & $18(14-20)$ \\
\hline Frenchay Activites Index & $9.5(4-21)$ & $12(5-24)$ & $14.5(3.5-26)$ \\
\hline GHQ-28 score & $3(1-6)$ & $4(1-8)$ & $5(2-8)$ \\
\hline PSE total symptom score & $4(2-7)$ & $5(2-9)$ & $5(2-9)$ \\
\hline
\end{tabular}


at both 6 and 12 months. Odds ratios and 95\% confidence intervals were calculated but the differences did not reach statistical significance.

There was some evidence of differences between the three groups in satisfaction with hospital care, with patients randomised to treatment as usual being the least satisfied. Patients randomised to problem-solving were more satisfied than patients who received treatment as usual with three aspects of care after discharge. Odds ratios $(95 \% \mathrm{CI})$ were calculated but only three items were significantly different at 6 months: the hospital staff attended to my needs; satisfaction with support to help cope with feelings about stroke and satisfaction with interest shown in worries and concerns of patient since stroke. At 12 months only satisfaction with information received about voluntary organisations was significantly better in the problem-solving therapy group. See Tables 3 and 4 .

More patients in the problem-solving group dropped out of the study than the other two groups, mainly due to a higher refusal rate. One possibility is that patients who received less therapy, or who were doing less well in therapy, were more likely to drop out. However, if we assume that the 18 problem-solving patients who refused 12 month follow-up had the same GHQ scores as the mean of followed-up patients in the treatment as usual group, the mean GHQ score in the problemsolving group would have been 4.6 rather than 4.5 , with no change in the statistical significance of our result.

The 17 items of the satisfaction scale showed only 1 significant difference across all 3 groups, which is consistent with what would be expected in this number of secondary analyses.

To test the extent of masking we asked the interviewer to guess the allocation of the last 127 patients, after their 12 month interview. The interviewer guessed correctly in $65(51.2 \%)$ patients (kappa $=0.26, p<.001)$, suggesting that some unmasking had occurred. Treatment as usual was the most frequent guess.

\section{Discussion}

There is some evidence from our study that problemsolving therapy can be effective in reducing emotional disorder at 12 months after stroke though the benefits observed are modest. The therapy group had lower GHQ scores at 12 months; and were more satisfied with aspects of their care related to psychological outcomes at 6 months. There was no difference in activity scores; indeed patients in the therapy group were the least active of the 3 groups. It is disappointing that therapy had no effect on social activity, but perhaps not surprising given that our chosen measure for this outcome (the Frenchay Activities Index) is heavily dependent on basic physical abilities. We surmise that patients' activities were limited more by the disabling effects of their stroke than by their inclination to be socially active.

We chose GHQ as our primary outcome because it is one of the most widely used and validated questionnaires to assess mood and because it has been tested in numerous populations including people with stroke [18]. When we analysed the data on the basis of presence of psychiatric disorder, defined according to research interview, the difference was no longer-significant. One possibility is that the intervention helps milder emotional disturbance but not more severe states. Another interpretation is that our study was under-powered to show a significant reduction in this more stringent test. It is also possible that the continuation of volunteer visits beyond the planned intervention period, something that occurred in a number of cases in our study, diluted any between-groups differences; for example explaining why the lower GHQ scores observed in the therapy group at 6 months did not reach significance.

Unlike many studies of psychological therapy we did not limit recruitment to patients with symptoms of mood disorder. Instead we used a broad recruitment strategy in order to test the effects of the intervention as a preventive treatment. We also thought it unlikely that a brief psychological treatment such as problem solving would have a meaningful effect on patients with an established mood disorder. We decided not to include patients in residential care, who live in environments where it can be difficult to be an active problem solver, and where it would be difficult to deliver the intervention effectively. We also excluded patients with levels of cognitive ability, speech and use of English that would make the delivery of a talking psychological therapy problematic.

We acknowledge that our recruitment strategies limit the generalisability of the results in a wider stroke population but we feel this is justified because the application of problem- solving therapy in practice would most likely be targeted at the community dwelling stroke patient with the potential to regain some degree of independence in daily living. If we assume that in routine practice therapy might be offered to those we excluded because they were in another trial, those who did not live locally and those who refused randomisation, then a total of $682 / 1487$ (46\%) stroke survivors might be suitable for such a brief therapy.

Overall the results of this trial are encouraging but nevertheless we recognise that a number of limitations need to be considered. Multiple item testing is a problem that affects the measurement of satisfaction and quality of life measures. This study used a large number of outcome measures thereby increasing the possibility of chance findings. The primary outcome variable was GHQ score and this was significantly different between 
Table 3 Psychology, activity and proportion expressing dissatisfaction at 6 months after stroke

\begin{tabular}{|c|c|c|c|}
\hline Variable & $\begin{array}{l}\text { Problem solving } \\
\text { therapy } \mathrm{n}(\%)\end{array}$ & $\begin{array}{l}\text { Volunteer support } n \\
\text { (\%) OR (95\% Cl) }\end{array}$ & $\begin{array}{l}\text { Treatment as usual } \mathrm{n} \\
\text { (\%) OR (95\% Cl) }\end{array}$ \\
\hline \multirow[t]{2}{*}{ GHQ score $\geq 9$} & \multirow[t]{2}{*}{$28 / 126(22)$} & $33 / 127(26)$ & 37 / $126(29)$ \\
\hline & & $1.2(0.69,2.2)$ & $1.4(0.82,3.1)$ \\
\hline \multirow[t]{2}{*}{ PSE index of definition $\geq 5$} & \multirow[t]{2}{*}{$23 / 126(18)$} & $31 / 128(24)$ & $34 / 124(27)$ \\
\hline & & $1.4(0.78,2.6)$ & $1.7(0.93,3.1)$ \\
\hline \multirow[t]{2}{*}{ Major depression } & \multirow[t]{2}{*}{$23 / 126(18)$} & $34 / 128(27)$ & 35 / $124(28)$ \\
\hline & & $1.6(0.89,2.9)$ & $1.8(0.97,3.2)$ \\
\hline \multirow[t]{2}{*}{ Any depression } & \multirow[t]{2}{*}{37 / $126(29)$} & $42 / 128(33)$ & 47 / $124(38)$ \\
\hline & & $1.2(0.72,2.1)$ & $1.5(0.87,2.5)$ \\
\hline \multirow{2}{*}{$\begin{array}{l}\text { I have been treated with kindness and respect by the hospital staff, number } \\
\text { dissatisfied }\end{array}$} & \multirow[t]{2}{*}{$2 / 121(2)$} & $7 / 125(6)$ & $1 / 125(0.8)$ \\
\hline & & $3.5(0.72,17)$ & $0.48(0.04,5.4)$ \\
\hline \multirow[t]{2}{*}{ The hospital staff attended well to my personal needs, number dissatisfied } & \multirow[t]{2}{*}{$4 / 121(3.3)$} & $12 / 125(10)$ & $3 / 125(2)$ \\
\hline & & $3.1(0.97,9.9)$ & $0.72(0.16,3.3)$ \\
\hline \multirow{2}{*}{$\begin{array}{l}\text { I felt able to talk to the hospital staff about any problems, number } \\
\text { dissatisfied }\end{array}$} & \multirow[t]{2}{*}{$13 / 120(11)$} & $12 / 124(10)$ & $11 / 125(9)$ \\
\hline & & $0.88(0.38,2.0)$ & $0.79(0.34,1.8)$ \\
\hline \multirow[t]{2}{*}{ I received all the information I wanted about my stroke, number dissatisfied } & \multirow[t]{2}{*}{$25 / 121(21)$} & $30 / 125(24)$ & $21 / 125(17)$ \\
\hline & & $1.2(0.66,2.2)$ & $0.77(0.41,1.5)$ \\
\hline \multirow{2}{*}{$\begin{array}{l}\text { The doctors have done everything they can to make me well again, } \\
\text { number dissatisfied }\end{array}$} & \multirow[t]{2}{*}{$7 / 121(6)$} & $10 / 124(8)$ & $6 / 124(5)$ \\
\hline & & $1.4(0.52,3.9)$ & $0.83(0.27,2.5)$ \\
\hline \multirow{2}{*}{$\begin{array}{l}\text { I am happy with the recovery I have made since my illness, number } \\
\text { dissatisfied }\end{array}$} & \multirow[t]{2}{*}{$24 / 121(20)$} & $25 / 125(20)$ & $22 / 123(18)$ \\
\hline & & $1.0(0.54,1.9)$ & $0.88(0.46,1.7)$ \\
\hline \multirow{2}{*}{$\begin{array}{l}\text { I am satisfied with the treatment the therapists (e.g. occupational, physio, } \\
\text { speech) have given me, number dissatisfied }\end{array}$} & \multirow[t]{2}{*}{$13 / 121(11)$} & $14 / 125(11)$ & $17 / 124(14)$ \\
\hline & & $1.0(0.47,2.3)$ & $1.3(0.61,2.8)$ \\
\hline \multirow{2}{*}{$\begin{array}{l}\text { I was given enough information about allowances \& services, number } \\
\text { dissatisfied }\end{array}$} & \multirow[t]{2}{*}{$17 / 114(15)$} & $18 / 123(15)$ & $25 / 120(21)$ \\
\hline & & $0.98(0.48,2.0)$ & $1.5(0.76,3.0)$ \\
\hline \multirow[t]{2}{*}{ Things were well prepared for my return home, number dissatisfied } & \multirow[t]{2}{*}{$13 / 114(11)$} & $18 / 123(15)$ & $15 / 121(12)$ \\
\hline & & $1.3(0.62,2.9)$ & $1.1(0.50,2.4)$ \\
\hline I am satisfied with the hospital outpatient services, number dissatisfied & $12 / 116(10)$ & $12 / 124(10)$ & $13 / 121(11)$ \\
\hline & & $0.93(0.40,2.2)$ & $1.0(0.45,2.4)$ \\
\hline The ambulance service is good and reliable, number dissatisfied & $10 / 115(9)$ & $6 / 122(5)$ & $9 / 119(8)$ \\
\hline & & $0.54(0.19,1.5)$ & $0.86(0.34,2.2)$ \\
\hline I get enough support from meals on wheels, home help, etc, number & $12 / 112(11)$ & $10 / 124(8)$ & $14 / 121(12)$ \\
\hline dis & & $0.73(0.30,1.8)$ & $1.1(0.48,2.5)$ \\
\hline I am satisfied with the service from my GP, number dissatisfied & $10 / 116(9)$ & $13 / 125(10)$ & $9 / 121(7)$ \\
\hline & & $1.2(0.52,2.9)$ & $0.85(0.33,2.2)$ \\
\hline I am satisfied with the support to help me cope with my feelings about the & $9 / 115(8)$ & $18 / 124(14)$ & $27 / 120(22)$ \\
\hline & & $2.0(0.86,4.6)$ & $3.4(1.5,7.6)$ \\
\hline I am satisfied with the interest shown in my worries and concerns since the & $11 / 115(10)$ & $22 / 124(17)$ & $27 / 120(22)$ \\
\hline & & $2.0(0.94,4.4)$ & $2.7(1.3,5.8)$ \\
\hline I was given enough information about voluntary organisations, number & $19 / 116(16)$ & $24 / 124(19)$ & $35 / 120(29)$ \\
\hline & & $1.2(0.63,2.4)$ & $2.1(1.1,3.9)$ \\
\hline I am satisfied that my family were encouraged to be involved in my care, & $9 / 112(8)$ & $6 / 120(5)$ & $8 / 119(7)$ \\
\hline & & $0.60(0.21,1.7)$ & $0.82(0.31,2.2)$ \\
\hline
\end{tabular}


Table 4 Psychology, activity and proportion expressing dissatisfaction at 12 months after stroke

\begin{tabular}{|c|c|c|c|}
\hline Variable & $\begin{array}{l}\text { Problem solving } \\
\text { therapy } \mathrm{n}(\%)\end{array}$ & $\begin{array}{l}\text { Volunteer support } n \\
\text { (\%) OR (95\% Cl) }\end{array}$ & $\begin{array}{l}\text { Treatment as usual } \mathrm{n} \\
\text { (\%) OR (95\% Cl) }\end{array}$ \\
\hline \multirow[t]{2}{*}{$\mathrm{GHQ} \geq 9$} & \multirow[t]{2}{*}{$17 / 116(15)$} & $26 / 124(21)$ & $28 / 123(23)$ \\
\hline & & $1.5(0.79,3.0)$ & $1.7(0.88,3.3)$ \\
\hline \multirow[t]{2}{*}{ PSE index of definition $\geq 5$} & \multirow[t]{2}{*}{$22 / 115(19)$} & $31 / 124(25)$ & $30 / 124(24)$ \\
\hline & & $1.4(0.76,2.6)$ & $1.3(0.72,2.5)$ \\
\hline \multirow[t]{2}{*}{ Major depression } & \multirow[t]{2}{*}{$21 / 115(18)$} & $33 / 124(27)$ & $31 / 124(25)$ \\
\hline & & $1.6(0.88,3.0)$ & $1.5(0.80,2.8)$ \\
\hline \multirow[t]{2}{*}{ Any depression } & \multirow[t]{2}{*}{$32 / 115(28)$} & $38 / 124(31)$ & $38 / 124(31)$ \\
\hline & & $1.1(0.64,1.9)$ & $1.1(0.63,1.9)$ \\
\hline \multirow{2}{*}{$\begin{array}{l}\text { I have been treated with kindness and respect by the hospital staff, number } \\
\text { dissatisfied }\end{array}$} & \multirow[t]{2}{*}{$1 / 111(0.9)$} & $3 / 115(3)$ & $2 / 121(2)$ \\
\hline & & $2.9(0.30,29)$ & $1.8(0.16,21)$ \\
\hline \multirow[t]{2}{*}{ The hospital staff attended well to my personal needs, number dissatisfied } & \multirow[t]{2}{*}{$4 / 111(4)$} & $6 / 115(5)$ & $7 / 121(6)$ \\
\hline & & $1.5(0.40,5.4)$ & $1.6(0.47,5.8)$ \\
\hline \multirow{2}{*}{$\begin{array}{l}\text { I felt able to talk to the hospital staff about any problems, number } \\
\text { dissatisfied }\end{array}$} & \multirow[t]{2}{*}{$9 / 111(8)$} & $12 / 115(10)$ & $11 / 121(9)$ \\
\hline & & $1.3(0.53,3.3)$ & $1.1(0.45,2.8)$ \\
\hline \multirow[t]{2}{*}{ I received all the information I wanted about my stroke, number dissatisfied } & \multirow[t]{2}{*}{$13 / 111(12)$} & $24 / 115(21)$ & $20 / 121(16)$ \\
\hline & & $2.0(0.95,4.1)$ & $1.5(0.70,3.2)$ \\
\hline \multirow{2}{*}{$\begin{array}{l}\text { The doctors have done everything they can to make me well again, } \\
\text { number dissatisfied }\end{array}$} & \multirow[t]{2}{*}{$4 / 111(4)$} & $8 / 114(7)$ & $7 / 121(6)$ \\
\hline & & $2.0(0.59,6.9)$ & $1.6(0.47,5.8)$ \\
\hline \multirow{2}{*}{$\begin{array}{l}\text { I am happy with the recovery I have made since my illness, number } \\
\text { dissatisfied }\end{array}$} & \multirow[t]{2}{*}{$20 / 111(18)$} & $26 / 115(23)$ & $28 / 120(23)$ \\
\hline & & $1.3(0.69,2.5)$ & $1.4(0.73,2.6)$ \\
\hline \multirow{2}{*}{$\begin{array}{l}\text { I am satisfied with the treatment the therapists (e.g. occupational, physio, } \\
\text { speech) have given me, number dissatisfied }\end{array}$} & \multirow[t]{2}{*}{$13 / 111(12)$} & $9 / 115(8)$ & $13 / 120(11)$ \\
\hline & & $0.64(0.26,1.6)$ & $0.92(0.40,2.1)$ \\
\hline \multirow{2}{*}{$\begin{array}{l}\text { I was given enough information about allowances \& services, number } \\
\text { dissatisfied }\end{array}$} & \multirow[t]{2}{*}{$12 / 107(11)$} & $21 / 112(19)$ & $17 / 119(14)$ \\
\hline & & $1.8(0.85,3.9)$ & $1.3(0.60,2.9)$ \\
\hline \multirow[t]{2}{*}{ Things were well prepared for my return home, number dissatisfied } & \multirow[t]{2}{*}{$9 / 107(8)$} & $18 / 111(16)$ & $17 / 118(14)$ \\
\hline & & $2.1(0.90,4.9)$ & $1.8(0.78,4.3)$ \\
\hline I am satisfied with the hospital outpatient services, number dissatisfied & $9 / 107(8)$ & $19 / 110(17)$ & $12 / 118(10)$ \\
\hline & & $2.3(0.98,5.3)$ & $1.2(0.50,3.0)$ \\
\hline The ambulance service is good and reliable, number dissatisfied & $7 / 108(6)$ & $6 / 106(6)$ & $5 / 118(4)$ \\
\hline & & $0.87(0.28,2.7)$ & $0.6(0.20,2.1)$ \\
\hline I get enough support from meals on wheels, home help, etc, number & $6 / 106(6)$ & $17 / 107(16)$ & $12 / 118(10)$ \\
\hline & & $3.1(1.6,8.3)$ & $1.9(0.68,5.2)$ \\
\hline I am satisfied with the service from my GP, number dissatisfied & $7 / 107(6)$ & $17 / 111(15)$ & $12 / 117(10)$ \\
\hline & & $2.6(1.0,6.5)$ & $1.6(0.62,4.3)$ \\
\hline I am satisfied with the support to help me cope with my feelings about the & $14 / 108(13)$ & $17 / 111(15)$ & $19 / 118(16)$ \\
\hline & & $1.2(0.57,2.6)$ & $1.3(0.61,2.7)$ \\
\hline I am satisfied with the interest shown in my worries and concerns since the & $13 / 108(12)$ & $16 / 111(14)$ & $23 / 117(20)$ \\
\hline & & $1.2(0.56,2.7)$ & $1.8(0.85,3.7)$ \\
\hline I was given enough information about voluntary organisations, number & $13 / 108(12)$ & $19 / 110(17)$ & $33 / 116(28)$ \\
\hline & & $1.5(0.71,3.3)$ & $2.9(1.4,3.7)$ \\
\hline I am satisfied that my family were encouraged to be involved in my care, & $7 / 107(6)$ & $10 / 108(9)$ & $11 / 116(9)$ \\
\hline nu & & $1.5(0.53,4.0)$ & $1.5(0.56,4.0)$ \\
\hline
\end{tabular}


the three groups, but mood was also assessed by GHQ caseness, total symptom score, PSE index of definition and major depression, at both 6 \& 12 months after stroke. However, it is important to note that all the significant differences favoured the therapy group, including a measure of satisfaction of many aspects of hospital and community care.

We also acknowledge the effect of interviewer bias and the extent of unmasking of the outcome interviewers to the patient's allocation but the influence of this effect on the results should not be overstated given that in almost $50 \%$ occasions the interviewer failed to guess the patient's allocation correctly. Furthermore, the two significant measures: the GHQ and the satisfaction scale, were self-report measures thus lessening the effect of interviewer bias.

The impact of the volunteer visitors is harder to discount as we did not control what they were doing in their intervention. The results of a small diary and focus group study suggest that there was considerable variation between the volunteers, and that the type of intervention they provided was driven by their personal experience of stroke.

\section{Conclusion}

Our trial randomised 150 patients to receive a shortterm psychological treatment and demonstrated that problem-solving therapy has potential value for the reduction or prevention of emotional disorders after stroke. Benefits of interventions have two components: the specific effects of the treatment itself and the perception that the therapy is being given. In this study, as a placebo arm was not possible, we controlled for nonspecific effects using the volunteer support arm to which a similar number of patients were randomised. Replication is needed to confirm our findings, preferably in multi-centre trials with larger sample sizes, and incorporating some form of process measure in an attempt to gain a better understanding of how patients make use of the therapy intervention.

\section{Abbreviations}

Cl: Confidence interval; GHQ-28: General health questionnaire 28-item; IQR: Interquartile range; MMSE: Mini-Mental State Examination; NHS: National health service; PSE: Present state examination (short form)

\footnotetext{
Acknowledgements

We thank the patients and carers who participated in the trial, and the volunteer visitors for their enthusiasm and time. We also thank the staff of the Leeds Stroke Database, the local hospital and community trusts, social services departments and general practices for assisting the data collection, and those who worked on the study.
}

\section{Authors' contributions}

Funding was obtained by $\mathrm{AH}$ and JB. The interventions were designed and the study implemented by $\mathrm{AH}, \mathrm{PK}$ and $\mathrm{CW}$. AV analysed the clinical data. $\mathrm{KH}$ critically reviewed and revised the paper. All authors contributed to the writing of the paper. All authors have access to the data and hold final responsibility for the decision to submit for publication. All authors have read and approved the final manuscript for publication.

\section{Funding}

This research was funded by the United Kingdom NHS Research and Development programme in cardiovascular disease and stroke. The grant holders were Allan House, John Bamford, Graham Mulley (Leeds), Anne Forster, John Young (Bradford), Trevor Sheldon, Ken Wright (York). The funding body had no role in the design of the study or the collection, analysis, and interpretation of data nor in writing the manuscript.

\section{Availability of data and materials}

The data that support the findings of this study are available from the author upon reasonable request.

\section{Ethics approval and consent to participate}

Ethical approval was granted by the local NHS Research Ethics committees in Bradford and Leeds:

St. James's University Hospital Ref: 01/182.

Leeds General Infirmary Ref: CA02/131

Bradford Hospitals NHS Trust Ref: 02/06/222.

All patients participating in the study gave written informed consent. No individual participants are identified in the paper.

\section{Consent for publication}

Not Applicable.

\section{Competing interests}

The authors declare that they have no competing interests.

\section{Author details}

${ }^{1}$ Leeds Institute of Health Sciences, University of Leeds, Worsley Building (Rm 11.57), Clarendon Way, Leeds LS2 9NL, UK. ${ }^{2}$ Department of Health Sciences and the Hull York Medical School, University of York, York YO10 5DD, UK. ${ }^{3}$ Centre for Clinical Brain Sciences, National CJD Research and Surveillance Unit, Bryan Matthews Building, Western General Hospital, Crewe Road, Edinburgh EH4 2XU, UK. ${ }^{4}$ Leeds Teaching Hospitals Trust, Great George Street, Leeds LS1 3EX, UK. ${ }^{5}$ The University of Manchester, Oxford Rd, Manchester M13 9PL, UK.

Received: 30 October 2018 Accepted: 31 May 2019

Published online: 14 June 2019

\section{References}

1. Hackett ML, Anderson CS, House A, Halteh C. Interventions for preventing depression after stroke. Cochrane Database Syst Rev. 2008;(3). CD003689. https://doi.org/10.1002/14651858.CD003689.pub3.

2. Hackett ML, Anderson CS, House A, Xia J. Interventions for treating depression after stroke. Cochrane Database Syst Rev. 2008;(4):CD003437. https://doi.org/10.1002/14651858.CD003437.pub3.

3. Knapp P, Young J, House A, Forster A. Non-drug strategies to resolve psycho-social difficulties after stroke. Age Ageing. 2000;29(1):23-30.

4. Gao J, Lin M, Zhao J, Bi S, Ni Z, Shang X. Different interventions for postischaemic stroke depression in different time periods: a single-blind randomized controlled trial with stratification by time after stroke. Clin Rehabil. 2017;31(1):71-81.

5. Wu DY, Guo M, Gao YS, Kang YH, Guo JC, Jiang XL, Chen F, Liu T. Clinical effects of comprehensive therapy of early psychological intervention and rehabilitation training on neurological rehabilitation of patients with acute stroke. Asian Pac J Trop Med. 2012;5(11):914-6.

6. Hadidi NN, Huna Wagner RL, Lindquist R. Nonpharmacological treatments for post-stroke depression: an integrative review of the literature. Res Gerontol Nurs. 2017:10(4):182-95.

7. Mehta S, Pereira S, Janzen S, McIntyre A, McClure A, Teasell RW. Effectiveness of psychological interventions in chronic stage of stroke: a systematic review. Top Stroke Rehabil. 2012;19(6):536-44.

8. D'Zurilla TJ. Problem-solving therapy : a social competence approach to clinical intervention. New York: Springer Pub. Co; 1986.

9. Goldberg D. Use of the general health questionnaire in clinical work. Br Med J (Clin Res Ed). 1986;293(6556):1188. 
10. Wing JK, Cooper JE, Sartorius N. Present state examination. London: Cambridge University Press; 1974.

11. Folstein MF, Folstein SE, McHugh RR. Mini mental state' a practical method for grading the cognitive state of pateints for the clinician. J Psychiatr Res. 1975;12:189-98.

12. Zelen M. A new design for randomized clinical trials. N Engl J Med. 1979; 300(22):1242-5.

13. Dempster C, Knapp P, House A. The collaboration of carers during psychological therapy. Ment Health Nurs. 1998;18:24-7.

14. Mahoney F, Barthel D. Functional evaluation: the Barthel index. Md State Med J. 1965;14:61-5.

15. Wade DT, Legh-Smith J, Hewer RL. Social activities after stroke: measurement and natural history using the Frenchay activities index. Int Rehabil Med. 1985;7(4):176-81.

16. Pound P, Gompertz P, Ebrahim S. Patients' satisfaction with stroke services. Clin Rehabil. 1994;8(1):7-17.

17. Freedland KE, Mohr DC, Davidson KW, Schwartz JE. Usual and unusual care: existing practice control groups in randomized controlled trials of behavioral interventions. Psychosom Med. 2011;73(4):323.

18. Robinson RG, Price TR. Post-stroke depressive disorders: a follow-up study of 103 patients. Stroke. 1982;13(5):635-41.

\section{Publisher's Note}

Springer Nature remains neutral with regard to jurisdictional claims in published maps and institutional affiliations.

Ready to submit your research? Choose BMC and benefit from:

- fast, convenient online submission

- thorough peer review by experienced researchers in your field

- rapid publication on acceptance

- support for research data, including large and complex data types

- gold Open Access which fosters wider collaboration and increased citations

- maximum visibility for your research: over $100 \mathrm{M}$ website views per year

At $\mathrm{BMC}$, research is always in progress.

Learn more biomedcentral.com/submissions 